\title{
Anaesthesia drug cost, control and utilization in Canada
}

common clinical scenarios cheaper agents were preferred and syringe re-use was surprisingly common.

Objectif: Discuter de l'attitude des anesthésistes en exercice au regard des agents anesthésiques en ce qui concerne les coûts, le contrôle, leur utilisation et l'approche pédagogique et déterminer leur façon de les utiliser dans des situations cliniques habituelles.

Méthode: Un questionnaire a été expédié par la poste aux chefs de départements de tous les hôpitaux canadiens de plus de 200 lits $(n=187)$. Les réponses ont été analysées avec le tests chi au carré et $T: P<0,05$ était considéré comme significatif.

Résultats: Soixante-huit pour cent ont répondu. Quatre-vingtquatre pour cent considèrent le coût lors du choix d'un anesthésique, $63,7 \%$ ont répondu que des produits moins coûteux pouvaient être utilisés sans diminuer la qualité des soins et 46,3 sont en faveur de restreindre l'accès aux produits dispendieux. Actuellement, seulement 32,8\% des hôpitaux imposent des restrictions. Des directives issues du département sont préférées par $82,1 \%$ des répondants. Cinquantetrois pensent que la formation des résidents quant aux cô̂ts agents est insuffisante, et $57,4 \%$ que l'enseignement en soi justifié l'usage des agents dispendieux. La plupart des répondants $(69,8-96,8 \%)$ pensent connaître le coût des agents usuels, mais plusieurs utilisent des agents moins coûteux comme l'halothane, le curare et la morphine et $61 \%$ réutilisent les seringues contenant les surplus. Quelques différences ont été notées entre les hôpitaux d'enseignement er les autres hôpitaux.

Conclusion: Ces anesthésistes démontrent leur intelligence de la pharmacoéconomie, croient que des agents anesthésiques de moindre coût peuvent être utilisés sans compromettre la qualité des soins, ne constatent des politiques restrictives que dans un petit nombre d'hoppitaux et pensent que l'enseignement pourrait être amélioré quant aux coûts. Plusieurs manifestent leur accord aux directives d'exercice. Dans les situations courantes, les agents moins chers sont préférés et la réutilisation des seringues se pratique de façon déconcertante.

As health care providers in Canada strive to maintain high quality care in the face of static or decreased funding, there is heightened awareness of the importance of 
cost containment and therapeutic cost/benefit relationships. Anaesthetists are not immune from pressures to trim costs and justify expenditures. Drug costs are one of the components of the total cost of anaesthesia services, and anaesthesia pharmacoeconomics is a newly recognized area of study.' Expenditure on anaesthesia drugs accounts for over one-third of the non-professional costs of anaesthesia care, and about $10 \%$ of a hospital's drug budget. ${ }^{2}$ Although anaesthesia drug costs may represent only $0.3 \%$ of a Canadian hospital's total budget, ${ }^{2}$ some drugs are very expensive and may greatly increase the total costs of anaesthesia care.

A recent editorial indicated the importance of "responsible choices" in the use of costly pharmaceuticals, ${ }^{3}$ and others have decried the lack of useful cost information in clinical investigations and scientific abstracts in the anaesthesia literature. ${ }^{4-7}$ Where the efficacy and safety of two drugs is equivalent, the multiple factors that determine an anaesthetist's choice of agent are likely to include cost, but also previous experience of the practitioner and information from continuing medical education endeavours, peer-reviewed literature, advertisements and pharmaceutical industry representatives. $^{8}$ Other factors are due to patient considerations, including anticipated complications, convenience and expediency. ${ }^{8}$ Anaesthetists have been encouraged to select drugs with cost-benefit relationships in mind, ${ }^{5.9}$ but there are few studies of the costs versus benefits of anaesthesia drugs to guide clinicians making these choices. Part of the problem is that while the dollar cost of drugs is relatively easy to measure, benefits are more difficult to gauge. For example, how is a monetary value assigned to benefits such as freedom from pain and suffering, lack of nausea and vomiting, and early discharge from ambulatory surgical units?

There is a paucity of data also on how individual anaesthetists and hospitals deal with drug cost control and utilization. Therefore we aimed to determine the attitudes of anaesthetists who head departments in the larger Canadian teaching and non-teaching hospitals to issues of drug cost, control and utilization. Specifically, we were interested in assessing whether respondents felt cost considerations were important, whether expensive drugs were overused, what restrictions are or should be in place, and how costs should be controlled. We planned to assess respondents' subjective knowledgc of actual drug costs and the sources from which they obtain information on drug cost. We aimed also to examine the differences between anaesthetists from teaching and non-teaching hospitals, and their opinions about the pharmacoeconomic education of anaesthesia residents. We presented the respondents with three common clinical scenarios to document patterns of drug usage, focusing on a few expensive or inexpensive agents. Finally, we decided to determine the proportion of anaesthetists who reuse syringes containing residual anaesthesia drugs from previous patient administration, a practice which may be cost-saving but possibly unsafe. ${ }^{10.11}$

\section{Methods}

A four-page questionnaire was mailed to the heads of anaesthesia departments in all Canadian hospitals with more than 200 beds $(n=187)$. These hospitals were identified from a database held by the Canadian Hospital Association.* The names of the respondents and the hospital were not identified in the questionnaire. A second mailing was done after an interval of six weeks to remind those who had not yet responded to do so.

The content of the questionnaire encompassed important pharmacoeconomic issues identified from the literature and by polling several members of the academic community (see Acknowledgments). A pilot study was conducted on 12 anaesthetists of the Toronto Western Division, Toronto Hospital. The final questionnaire was formulated based on feedback from this study group. The questionnaire comprised five sections (see Appendix). In Section I, identifying data, including type of hospital (teaching or non-teaching), number of operating rooms, anaesthesia qualification (Fellowship, Diploma, or none) and duration in anaesthesia practice, were obtained. Section II contained questions pertaining to respondents' attitudes toward the cost and control of anaesthesia drugs. Section III addressed the issues of education about drug costs and the sources from which knowledge of drug costs was obtained. Section IV asked respondents whether they knew the costs of 13 commonly used drugs (pancuronium, d-tubocurarine, vecuronium, atracurium, midazolam, thiopentone, propofol, fentanyl, alfentanil, sufentanil, halothane, enflurane and isoflurane). Finally, Section $V$ presented three clinical scenarios involving general anesthesia for common surgical procedures in ASA I patients (outpatient pelvic laparoscopy lasting $20-30 \mathrm{~min}$, inpatient hysterectomy lasting 90-120 min, outpatient 5-10 $\mathrm{min}$ mask anaesthetic) to determine patterns of drug use. Section $\mathrm{V}$ also contained a question about the re-use of syringes that had already been used to administer drug to previous patients.

Data are presented as either cumulative totals or percentages throughout the text, figures and tables. Data were analyzed with chi-square and $\mathrm{t}$ tests where appropriate; $P<0.05$ was considered significant.

*Canadian Hospital Association, 17 York Strcet, Suite 100, Ottawa, Ontario K1M 9J6. 


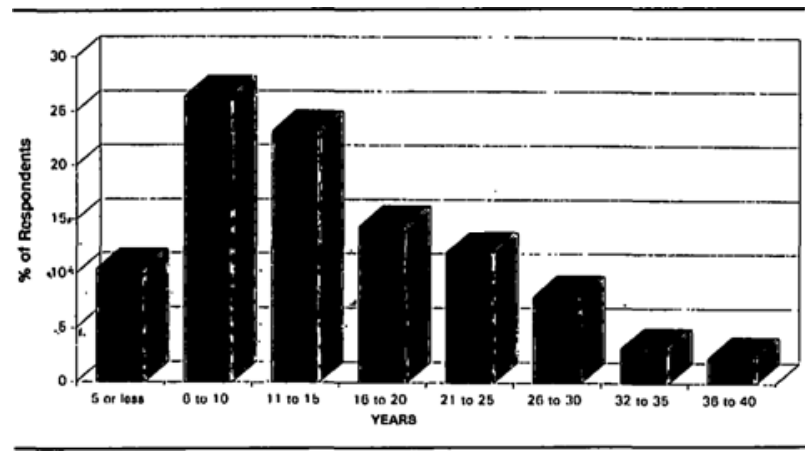

FIGURE I Years of experience of respondents.

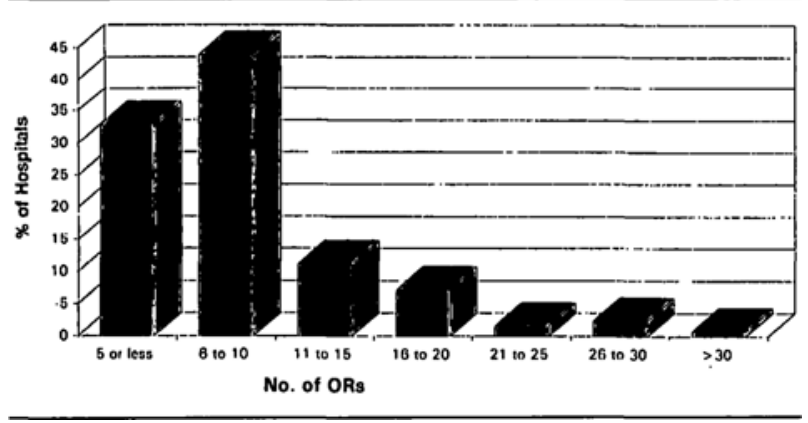

FIGURE 2 Number of ORs in hospitals of respondents.

\section{Results}

\section{Response rate and demographics}

Out of 187 Canadian hospitals with more than 200 beds, four did not have an anaesthesia department. Completed questionnaires were received from $125(68.3 \%)$ of the remaining 183 hospitals, of which $50(40.0 \%)$ were teaching hospitals. One hundred and fifteen respondents (92.0\%) possessed anaesthesia specialty certification. Four respondents $(3.2 \%)$ had an anaesthesia diploma, and five $(4.0 \%)$ had neither anaesthesia specialty certification nor a diploma. More than two thirds of respondents $(87 / 125,69.6 \%)$ had been in practice for ten years or more (Figure 1), and $37(29.6 \%)$ of these had practiced anaesthesia for 20 or more years. Hospitals with ten or fewer operating rooms comprised $76.8 \%(96 / 125)$ of the sample (Figure 2).

\section{Control of drug costs}

Ninety-four per cent (118/125) of respondents stated that considerations of cost affect the choice of the drugs they administer. Overall, $63.7 \%$ (79/124) believed that greater use of less expensive drugs could be used in their practice without decreasing the quality of care, more so in teaching hospitals $(41 / 48,85.4 \%)$ than in non-teaching hospitals $(38 / 68,55.9 \%)(P<0.001)$. When asked

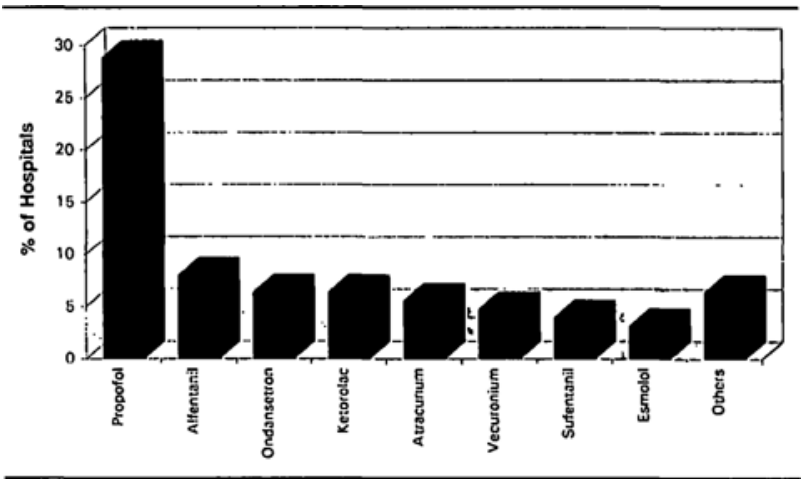

FIGURE 3 Drugs that are restricted.

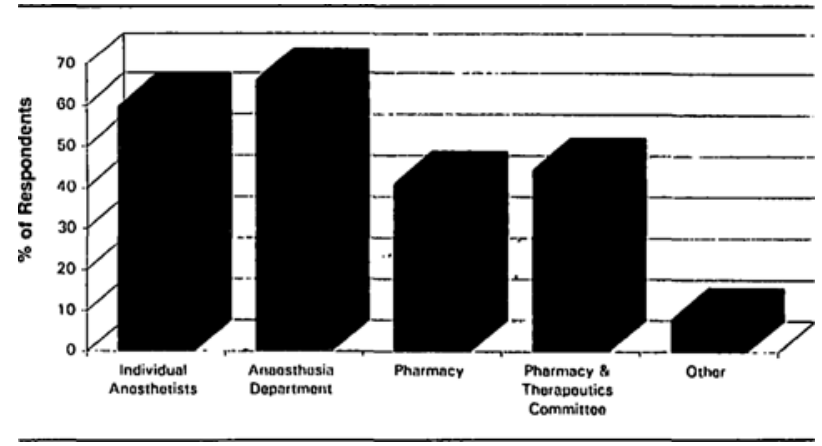

FIGURE 4 Who is responsible for drug cost control in your hospital?

whether they felt that expensive drugs were over-utilized in their own hospital, most respondents $(70 / 116,60.3 \%)$ disagreed. When analyzed by hospital type, those in non-teaching hospitals $(46 / 67,68.7 \%)$ were more likely to disagree with this statement than their counterparts in teaching hospitals $(24 / 49,49.0 \%)(P<0.05)$.

Almost half $(57 / 123,46.3 \%)$ of the respondents indicated that it was justified to restrict access to certain anaesthesia drugs because of their expense. More of those in teaching hospitals favoured restriction (29/47, $61.7 \%)$ than in non-teaching institutions $(28 / 70,40.0 \%)$ $(P<0.05)$.

Less than one third $(41 / 125,32.8 \%)$ of the hospitals currently restricted the utilization of more expensive anaesthesia agents, most commonly propofol (36/125, $28.8 \%)$, ondansetron $(8 / 125,6.4 \%)$, ketorolac $(8 / 125$, $6.4 \%)$, atracurium $(7 / 125,5.6 \%)$ and vecuronium $(6 / 125,4.8 \%)$ (Figure 3).

Responsibility for measures to control anaesthesia drug costs in these hospitals was not allocated to any one group but was shared amongst the anaesthesia department $(82 / 124,66.1 \%)$, individual anaesthetists $(74 / 124,59.7 \%)$, the pharmacy/therapeutics committee (or equivalent) $(55 / 125,44.0 \%)$ and the hospital pharmacy $(51 / 125,41.1 \%$ ) (Figure 4 ). Almost half the 


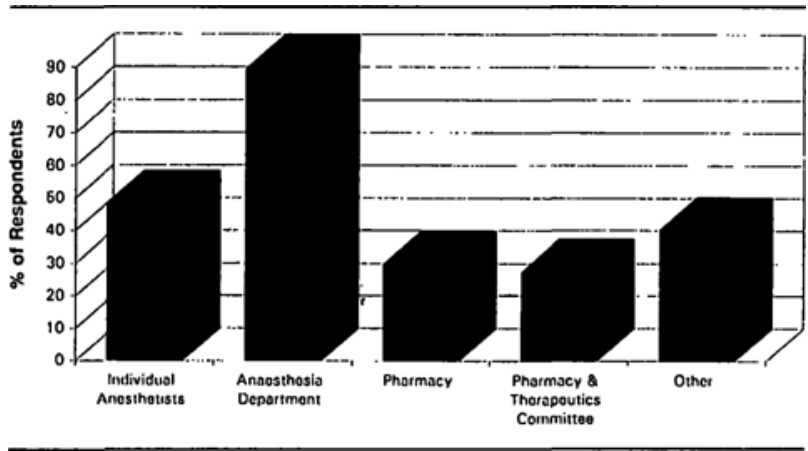

FIGURE 5 Who should be responsible for drug cost control?

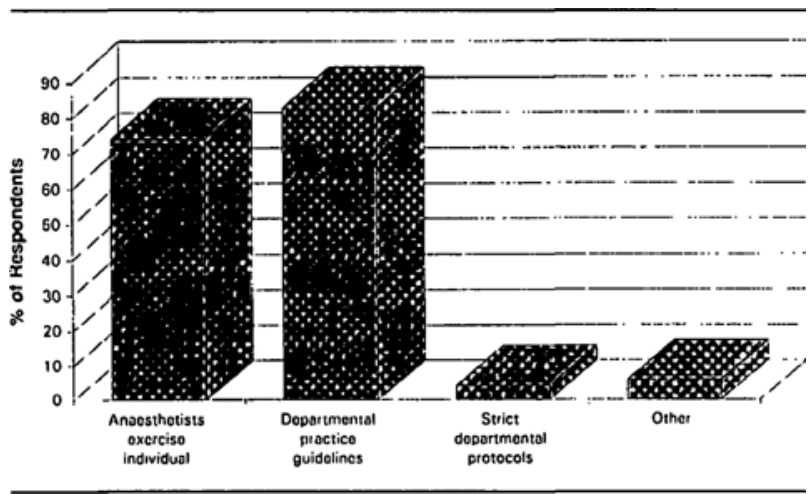

FIGURE 6 How should costs be controlled?

respondents $(60 / 123,48.8 \%)$ agreed that the anaesthesia department should be responsible for control; almost as many $(59 / 123,48.0 \%)$ indicated that individual anaesthetists acting independently should be responsible; $27.6 \%(34 / 123)$ would have included the pharmacy/therapeutics (or equivalent) committee (Figure 5). A majority $(91 / 123,74.0 \%)$ supported the idea that anaesthetists should exercise individual judgment as a cost-control measure, but even more $(101 / 123,82.1 \%)$ favoured the application of departmental practice guidelines. Only $4.1 \%(5 / 123)$ selected strict departmental practice protocols as a method of cost-control (Figure 6).

\section{Residency training}

Although most $(70 / 122,57.4 \%)$ respondents considered that the teaching of residents justified the use of expensive drugs where an acceptable cheaper alternative was available, almost a third disagreed $(40 / 122,32.8 \%)$. The majority $(105 / 123,85.4 \%)$ indicated that they were not adequately educated about drug cost during their own training, and $53.1 \%$ (26/49) of teaching hospital anaesthetists concluded that education of residents about drug costs today was inadequate.

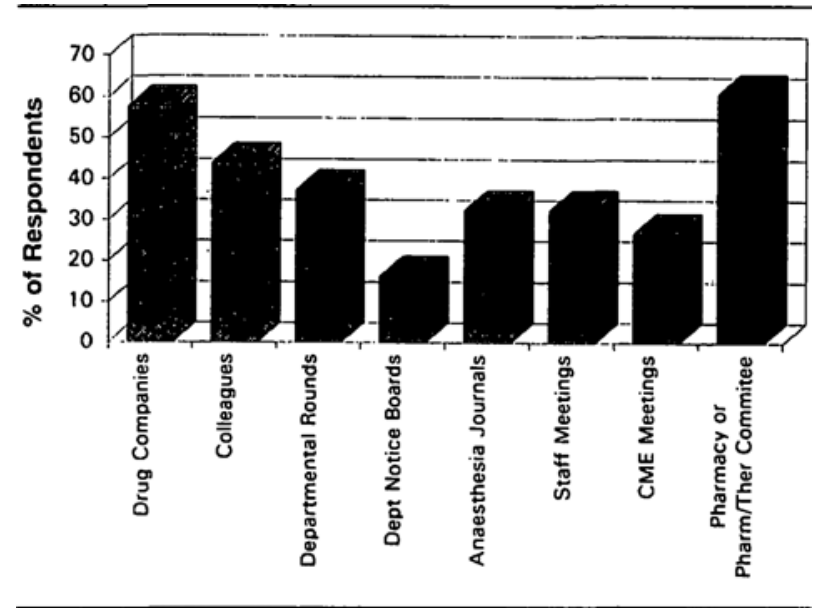

FIGURE 7 From where do you oblain inforimation about drug costs?

\section{Knowledge of drug costs}

The respondents obtained their information about drug costs from a variety of sources, including drug companies $(71 / 123,57.7 \%)$, hospital pharmacy or pharmacy \& therapeutics committees $(65 / 123,52.8 \%)$, colleagues (53/123, 43.1\%), departmental rounds $(45 / 123,36.6 \%)$, anaesthesia staff meetings $(39 / 123,31.7 \%)$, anaesthesia journals $(39 / 123,31.7 \%)$, CME meetings (34/123, $27.6 \%)$ and departmental notice boards $(20 / 123,16.2 \%)$ (Figure 7).

A majority of respondents answered yes to the question "do you know the (relative) cost of the following drugs?" which referred to each drug in a list of thirteen commonly used agents (pancuronium, d-tubocurarine, vecuronium, atracurium, midazolam, thiopentone, propofol, fentanyl, alfentanil, sufentanil, halothane, enflurane, isoflurane). The percentage of positive answers ranged from $69.8 \%(81 / 116)$ (sufentanil) to 96.8\% (124/125) (propofol). Teaching hospital anaesthetists were more likely to know the cost of these drugs than non-teaching hospital anaesthetists $(P<0.05)$ (Table).

\section{Patterns of drug use}

Few anaesthetists indicaled that they would prepare prophylactic vasopressor before administering general anaesthesia for outpatient laparoscopy $(17 / 124,13.7 \%)$, inpatient hysterectomy $(20 / 123,16.3 \%)$ or outpatient mask anaesthesia $(11 / 122,9.0 \%)$. In the case of an outpatient mask anaesthetic, they were more likely to do so if they had been in practice ten years or less $(8 / 45$, $17.8 \%)$ than were those in practice $10-20 \mathrm{yr}(2 / 47$, $4.3 \%)$. Many of the respondents $(44.7 \%, 55 / 123)$ drew up prophylactic atropine for outpatient laparoscopy, 
TABLE Differences between teaching (TH) and non-teaching hospitals (NTH)

\begin{tabular}{llll}
\hline & \multicolumn{2}{l}{ Positive responses } \\
\cline { 2 - 4 } & $T H(\%)$ & $N T H(\%)$ & $P$ value \\
\hline I Drug costs known & & \\
- Pancuronium & 96.0 & 70.0 & $<0.01$ \\
- Vecuronium & 96.0 & 8.3 .6 & $<0.05$ \\
- Atracurium & 94.0 & 78.4 & $<0.05$ \\
- Midazolam & 96.0 & 76.7 & $<0.005$ \\
- Entlurane & 83.3 & 61.1 & $<0.01$ \\
- Alfentanil & 89.6 & 74.0 & $<0.05$ \\
- Sufentanil & 80.9 & 62.3 & $<0.05$ \\
2 Could usc less cxpensive drugs without decreased quality of care & 85.4 & 55.9 & $<0.001$ \\
3 Expensive drugs over-utilized in your hospital & 31.3 & 51.0 & $<0.05$ \\
4 Restriction of expensive drugs justified & 61.7 & 40.0 & $<0.05$ \\
5 Re-use of syringes & 49.0 & 68.9 & $<0.05$ \\
\hline
\end{tabular}

inpatient hysterectomy $(44.4 \%, 55 / 124)$, and for an outpatient mask anaesthetic $(37.4 \%, 46 / 123)$.

Most respondents $(104 / 120,86.7 \%)$ would use a propofol induction in $20-30 \mathrm{~min}$ laparoscopies and 5-10 min mask anaesthetics (110/123, 89.4\%) but much less often $(38 / 122,31.1 \%)$ for $90-120 \mathrm{~min}$ hysterectomies. Propofol infusions would not commonly be used for a laparoscopic procedure $(17 / 120,14.2 \%)$. Only $7.4 \%(9 / 122)$ of respondents indicated the routine use of ondansetron and $10.5 \%(13 / 124)$ the use of ketorolac for outpatient laparoscopy. d-Tubocurarine $(25 / 121,20.7 \%)$ would still be used for an inpatient hysterectomy, as would morphine $(57 / 123,46.3 \%)$, but atracurium or vecuronium $(65.3 \%)$ are more usual choices.

Only $4.6 \%(2 / 44)$ of respondents in practice <ten years, $19.1 \%(9 / 47)$ of those in practice $10-20 \mathrm{yr}$, and $25.0 \%(8 / 32)$ of those working for $20 \mathrm{yr}$ or more would use halothane during an outpatient laparoscopy, $(P<$ $0.05)$. Almost a third $(40 / 122,32.8 \%)$ would use halothane for maintenance during a mask anaesthetic. More $(22 / 46,47.8 \%)$ of those with 10-20 years experience would do so than respondents with <ten years experience $(7 / 44,15.9 \%)(P<0.005)$.

\section{Syringe re-use}

The majority of respondents $(75 / 123,61.0 \%)$ would administer unused drug from a syringe previously used for a different patient, with precautions to prevent contamination. This practice was especially prevalent in non-teaching hospitals $(51 / 74,68.9 \%)$ compared with teaching hospitals $(24 / 49,49.0 \%)(P<0.05)$.

\section{Discussion}

This study shows that the heads of anaesthesia departments in major Canadian hospitals were aware of pharmacoeconomic issues. They indicated that more use of less expensive anaesthetic agents could be made without decreasing the quality of care, and that education about drug cost could be improved. Most respondents (82.1\%) favoured the introduction of departmental practice guidelines, but not strict protocols, for cost control. Almost half (46.3\%) were in favour of restricted access to expensive agents, but in most institutions restrictions were not currently in place. In their own practice, many of these anaesthetists routinely used inexpensive agents and $61.0 \%$ commonly administered unused drug from syringes previously used for different patients.

Because of the difficulty in determining the varying costs of drugs to different hospitals across the country, respondents' knowledge of the actual cost of individual agents was not objectively evaluated, and cannot be assumed. Nevertheless, our finding that most respondents claimed to know the relative costs of the usual agents supported our presumption that these anaesthetists were aware of drug cost issues.

One intriguing finding was the opinion of the majority (68.1\%) of our study group who indicated that cheaper drugs could be used without decreasing the quality of care. This may suggest a perceived overuse of expensive anaesthetic medications, without any documented corresponding therapeutic benefit. However, the majority $(60.3 \%)$ of our respondents shared the perception that this occurs in other hospitals and not in their own institutions.

A measure of the concern about control of drug costs was the finding that almost $50 \%$ of this group supported the restriction of access to expensive agents. However, despite this concern and the current tight fiscal conditions, not many hospitals (32.8\%) did so. Respondents were not asked about the nature of existing restrictions Not surprisingly, the most frequently restricted drug was propofol $(28.8 \%)$. The costs and benefits of propofol 
have been studied and there is strong support for its use in outpatient anaesthesia in the recent literature. ${ }^{12-15}$ The results suggest that responsibility for control of costs was not centralized but was shared amongst departments within each hospital. It is noteworthy that the pharmacy/therapeutics (or equivalent) committee shared responsibility for cost control in $44.3 \%$ of hospitals, but only $27.4 \%$ of respondents supported this participation. Also an important finding was that the majority $(82.1 \%)$ of the respondents were in favour of "departmental practice guidelines." Although controversial, practice guidelines or protocols are increasingly popular, and have become the intense focus of medical specialty organizations, insurers and governments. ${ }^{16}$ It may be difficult to reconcile the support for guidelines with the strongly held view $(74.0 \%)$ that anaesthetists should also "exercise individual judgment."

As the majority of respondents (53.1\%) in teaching hospitals considered that education of residents regarding drug costs was inadequate, residency programmes may wish to increase efforts to integrate teaching about drug costs and the principles of cost-effective prescribing into the curriculum. We did not determine the content of drug-cost education in residency programs. It was noted that such education had improved compared with the personal experience of the respondents as residents.

Our results indicated differences between anaesthetists in teaching hospitals and non-teaching hospitals. Teaching hospital anaesthetists more often indicated that they knew the costs of drugs and that they could safely use less expensive drugs. Paradoxically, these teaching hospital anaesthetists more frequently rejected the suggestion that expensive drugs were over-utilized in their own institutions. They would use cheaper drugs such as d-tubocurarine and morphine more often and were less likely to re-use syringes. We cannot speculate on the reasons for these differences without more specific data.

Hystercctomy, outpatient laparoscopy (including tubal ligation), and brief surgery that required a mask anaesthetic (including diagnostic and therapeutic dilatation and curettage) were the three commonest surgical procedures in Ontario during 1992-3.* This was the basis for the questions regarding actual patterns of drug use. Whilst it is difficult to generalize from these findings, the results indicated that there may be substantial use of cheaper agents such as d-tubocurarine, halothane and morphine, while more expensive drugs (ketorolac, ondansetron) and techniques (propofol infusion) are rarely utilized by these practitioners. Propofol does

*Personal communication, P. Brochu, Information Planning and Evaluation Branch, Ontario Ministry of Health. appear to be very popular for outpatient anaesthesia. We did not attempt to determine which of the multiple factors that influenced drug selection were operative in these cases. In the future such analyses may help to determine how and why practitioners make specific drug selections and how cost information alters their selections. ${ }^{17}$

The prophylactic preparation of atropine and vasopressor drugs before administration of anaesthesia to ASA I patients was a common practice. We surmise the drugs usually go unused and are discarded at the end of the day. We suggest that savings may accrue if these drugs are drawn up only when more likely to be administered. The re-use of syringes containing residual drugs is associated with the risk of cross-infection, and we would endorse the recommendation of the ASA $^{10}$ and others" that re-use be avoided despite the savings that may result from this practice.

This survey provided information about the departmental heads of anaesthesia in major hospitals, their attitudes and practice patterns. We chose these anaesthetists as our study group because they are "stakeholders" in the processes of cosl-control and their views are therefore of some consequence. They are involved in fiscal management and are therefore likely to be aware of costs and cost-restraint issues.

The high response rate $(68.3 \%)$ to the questionnaire strengthens the validity of our findings, but we cannot assume that the attitudes and knowledge of participants are representative of all practitioners. These are anacsthetists with many years of experience (Figure 1) and more than $90 \%$ hold specialist qualifications in anaesthesia (Table). The findings here may not apply, for cxample, to general practitioner-anaesthetists who provide approximately $25 \%$ of all anaesthesia services in Canada, primarily in rural areas. ${ }^{18}$

Amongst many pharmacoeconomic issues that require future study are the nature of actual and preferred restrictions on drug utilization, cost-benefit analyses, non-coercive methods of influencing drug prescribing behaviour, and analysis of regional and national patterns of drug usage. Given the relatively uniform nature of health care structures in Canada, it may be possible for national bodies such as the Canadian Anaesthetists Society to suggest guidelines for cost-beneficial practice, while hopefully leaving final control of drug selection in the hands of individual practitioners with whom the welfare of individual patients ultimately lies.

In summary, this survey achieved a high response rate from the group of anaesthetists who are in charge of the larger departments across Canada. It was their opinion that cheaper agents could be used without compromising the quality of care, but identified that few of their 
hospitals had policies that restrict drug use. Control and responsibility of drug utilization were shared within their hospitals and many approved the idea of practice guidelines, with retention of the exercise of individual judgment. Teaching of residents may provide additional justification for the use of more expensive drugs, but education of residents about drug costs was considered to be inadequate. In common clinical scenarios, these anaesthetists indicated their preference for cheaper agents, for the prophylactic preparation of atropine and vasopressors, and for the re-use of syringes. Differences between the attitudes and practice of respondents in teaching and non-teaching hospitals have been identified. Teaching hospital anaesthetists were more likely to know the cost of drugs, to use cheaper drugs, to support greater use of less expensive drugs, and to avoid re-use of syringes. In conclusion, the results indicated that the heads of the larger Canadian hospitals have a strong awareness of pharmacoeconomic issues and they may support practice guidelines for more cost effective drug application.

\section{Acknowledgments}

The authors thank all the heads of anaesthesia departments who participated in the survey. The authors wish to acknowledge the assistance of Dr. D.J. Doyle, Dr. D. Redelmeier, Dr. E. Michel, Prof. Chipman, Ms. Diane Irvine and Ms. Mary Wiktorowicz, in the design of this study.

\section{Appendix}

\section{Section I}

1 At which type of hospital are you based? (Teaching/ Non-teaching)

2 How many operating rooms in your hospital? (Include "main" OR's and day surgery OR's)

3 What is your qualification in anaesthesia? (Fellowship/Diploma/None)

4 How long have you been in anaesthesia practice?

\section{Section II}

1 Do considerations of cost affect your choice of the drugs you administer?

2 Do you believe less expensive drugs could be used in your practice without decreasing the quality of care?

3 Do you feel that expensive anaesthesia drugs are over-utilized in your hospital?

4 Do you believe it is justified to restrict access to certain anaesthesia drugs because of their expense?

5 Does your hospital currently restrict the utilization of more expensive anaesthesia agents? If yes, which drugs are restricted? If yes, has this significantly affected your practice?

6 Who is responsible for measures to control anaesthesia drug costs in your hospital?

7 In your opinion, who should be responsible for the control of anaesthesia drug costs in your hospital?

8 How should cost-control measures be applied?

\section{Section III}

1 Does the teaching of residents justify the use of an expensive drug, where an acceptable cheaper alternative is available?

2 During your own residency were you adequately educated about the cost of anaesthesia drugs?

3 Do you feel that anaesthesia residents today are adequately educated about anaesthesia drug costs?

4 Indicate the source(s) from which you obtain information about the costs of anaesthesia drugs.

\section{Section $V$}

1 An ASA I, 25-yr-old outpatient is booked for a pelvic laparoscopy. The procedure will take 20-30 min.

Do you draw up atropine? Do you draw up a vasopressor? Would you use halothane (if available) for maintenance? Would you use ondansetron (if available) to reduce post-operative nausea and vomiting? Would you use ketorolac for post-operative analgesia?

2 You are to administer a general anaesthetic to an ASA I inpatient undergoing hysterectomy, duration 90-120 min.

Do you draw up a vasopressor? Do you draw up atropine? Would you use propofol (if available) for induction? Would you use a propofol infusion? Would you use halothane (if available) for maintenance? Would you use curare (other than for defasciculation)? Would you use atracurium or vecuronium? Would you use morphine intraoperatively?

3 You are about to give a mask anaesthetic to a 25-yr-old ASA 1 patient, for outpatient surgery, of five to ten minute duration.

Do you draw up a vasopressor? Do you draw up atropine? Would you use propofol (if available) for induction? Would you use halothane (if available) for maintenance?

\section{References}

1 Bevan $D R$. Anaesthesia pharmacoeconomics (Editorial). Can J Anaesth 1993; 40: 693-5.

2 Hudson RJ, Friesen RM. Health care "reform" and the costs of anacsthesia (Editorial). Can J Anaesth 1993; 40: 1120-5.

3 Kapur PA. Pharmacy acquisition costs: responsible 
choices versus overutilization of costly pharmaceuticals (Editorial). Anesth Analg 1994; 78: 617-8.

4 Johnstone RE, Marlinec $C L$. Costs of anesthesia. Anesth Analg 1993; 76: 840-8.

5 Johnstone RE, Martinec CL. Anesthesia studics should include costs. Anesthesiology 1993; 79: 195-9.

6 Tuman $K J$, Ivankovich $A D$. High-cost, high-tech medicine: are we getting our money's worth? J Clin Anesth 1993; 5: 168-77.

7 Wetchler BV. Economic impact of anesthesia decision making: they pay the money, we make the choice. J Clin Anesth 1992; 4: 20S-24S.

8 Johnstone RE, Josefczyk $K G$. Costs of anesthetic drugs: experiences with a cost education trial. Anesth Analg 1994; 78: 766-71.

9 White $P F$, Watcha MF. Are new drugs cost-effective for patients undergoing ambulatory surgcry? Anesthesiology 1993; 78: 2-5.

10 Recommendations for infection control for the practice of anesthesiology. American Society of Anesthesiologists 1993.

11 Trepanier CA, Lessard MR, Brochu JG, Denault PH. Risk of cross-infection related to the multiple use of disposable syringes. Can J Anaesth 1990; 37: 156-9.

12 Marais $M L$, Maher $M W$, Wetchler $B V$, et al. Reduced demands on recovery room resources with propofol (Diprivan) compared to thiopental-isofluranc. Anesthesiology Review 1989; 16: 29-40.

13 Philip BK, Mushlin PS, Manzi D, Freiberger D, Roaf E. Isoflurane versus propofol for maintenance of anesthesia for ambulatory surgery: a comparison of costs and recovery profiles. Anesthesiology 1992; 77: A44.

14 Cooper CG, Maxwell V. Anaesthetic drug costs are nol increased by propofol. Can J Anaesth 1992; 39: 1000.

15 Sung $Y F$, Reiss $N$, Tilette $T$. The differential cost of anesthesia and recovery with propofol-nitrous oxide anesthesia versus thiopental sodium-isoflurane-nitrous oxide anesthesia. J Clin Anesth 1991; 3: 391-4.

16 Shomaker TS. Practice policics in ancsthesia: a foretastc of practice in the 21 st century. Anesth Analg 1995; 80: 388-403.

17 Horrow JC, Rosenberg H. Price stickers do not alter drug usagc. Can J Anaesth 1994; 41: 1047-52.

18 Duncan $P G, M c K i n s t r y ~ L$. Anesthesia in Canada's health care system. J Clin Anesth 1992; 4: 52-62. 